\title{
O conceito Marxiano de contradição na crítica à Filosofia do Direito de Hegel
}

Emmanuel Nakamura*

Resumo: Em sua crítica de 1843, Marx encontrou na Filosofia do Direito de Hegel (1821) uma contradição na repolitização da sociedade civil burguesa. Os interesses das instituições sociais só podem se realizar de maneira formal como assunto geral do Estado. Deste modo, tal processo de repolitização acaba repondo a separação entre sociedade civil burguesa e Estado. Meu objetivo é mostrar como, nesse debate com Hegel, Marx já apresenta um conceito de contradição que aponta para pressuposições históricas. Essa relação entre apresentação lógicosistemática e consideração histórica é fundamental para compreender posteriormente o programa da crítica à Economia Política.

Palavras-chave: Filosofia do Direito, contradição, pressuposição histórica.

Abstract: In his 1843 critique, Marx had found in Hegel's Philosophy of Right (1821) a contradiction in the re-politicization of the bourgeois civil society. The concerns of social institutions can only be formally realized as a matter of general rule of the state. Thus, this process of re-politicization just replaces the separation between civil society and state. My aim is to show how, in that particular debate with Hegel, Marx already exposes a concept of contradiction that indicates historical presuppositions. This relationship between logical-systematic exposition and historical consideration is essential to understand, later, the program of political economy's critique.

Keywords: Philosophy of Right, contradiction, historical presupposition.

* Doutorando em Filosofia na Humboldt-Universität zu Berlin e na Unicamp. Esta pesquisa é financiada pelo DAAD e pela FAPESP. E-mail: el.nakamura@gmx.de. 
Marx encontrou na apresentação hegeliana do poder legislativo nas "Linhas fundamentais da Filosofia do Direito" (1821) uma aporia na repolitização da sociedade civil burguesa. Para ele, as instituições sociais não podem aparecer imediatamente em seu significado político, pois isso significaria um retorno à Idade Média (MARX, 1982a, p. 79). As instituições sociais enquanto tal não têm significado político e só podem então ganhar "eficácia e significação política" quando elas renunciam aos seus interesses para que esses se realizem apenas de maneira puramente "formal" como "assunto geral" do Estado. Por isso, o burguês pode ser cidadão do Estado apenas como indivíduo, ou seja, enquanto ele está em "contradição com estas únicas comunidades ai-presentes" (ibidem, p. 86-7).

Tal crítica parte de um critério normativo: a teoria do ser genérico de Feuerbach. Quando Marx afirma que, na filosofia hegeliana do direito, "a propriedade privada tornou-se o sujeito da vontade" e que "a vontade nada mais é que o mero predicado da propriedade privada" (MARX, 1982a, p. 110), ele se apoia no argumento de Feuerbach de que Hegel fez uma inversão entre sujeito e predicado. Mesmo quando Marx afirma partir da efetividade empírica, ele ainda opera com o argumento feuerbachiano da inversão: "A lógica não serve como prova do Estado, mas o Estado como prova da lógica" (ibidem, p. 18).

No entanto, ao procurar mostrar o fundamento da inversão especulativa através da efetividade empírica, Marx formulou pela primeira vez o seu "primado da práxis" (ARNDT, 1985, p. 29). Em oposição à monarquia constitucional, Marx defende que a democracia é a forma de "autodeterminação do povo". Ele encontra aqui "o homem efetivo, o povo efetivo" (MARX, 1982a, p. 30-1). Através da democracia, a

\footnotetext{
${ }^{1}$ Em setembro de 1843, Marx escreveu para Arnold Ruge: “Todo nosso fim não pode consistir em nada mais, como também é o caso na crítica da religião de Feuerbach, que trazer as questões religiosas e políticas para a forma autoconsciente e humana" (MARX, 1975a, p. 56).
} 
constituição aparece como um "produto livre do homem". Entretanto, ela é defendida por Marx como uma afirmação, sem comprovação, contra a monarquia e, nesse sentido, ela aparece simplesmente como uma imediaticidade não-mediada ${ }^{2}$.

No entanto, Marx não parece se apoiar apenas na crítica da religião de Feuerbach, mas também em uma análise do processo histórico de surgimento das modernas constituições europeias (YILDIZ, 2008, p. 117). Através dessa análise, ele pôde então afirmar que, na Alemanha, o que estava em jogo não era a "suspensão" dos problemas sócio-políticos, como na Inglaterra e na França, mas sim a "continuação" até as últimas consequências e não a sua "solução", mas sim a "colisão" (MARX, 1982b, p. 174). Tal diagnóstico da situação na Alemanha se apoiava em uma análise histórica dos Estados europeus.

Minha hipótese é que não apenas a referência à crítica feuerbachiana da religião, mas antes a consideração histórica nos permite compreender a crítica de Marx de 1843 à representação política na "Filosofia do Direito" (1821) de Hegel. Meu objetivo é mostrar como, nesse debate com Hegel, Marx já apresenta um conceito de contradição que aponta para pressuposições históricas. Essa relação entre apresentação lógico-sistemática e consideração histórica é fundamental para compreender o programa da crítica à Economia Política.

II

De acordo com o comentário de Riedel (1982, p. 116-139), em "Die Rezeption von Nationalökonomie", Hegel só formulou claramente

\footnotetext{
2 Para Theunissen (1978, p. 485), Marx acredita que: “(...) o indivíduo humano só pode se realizar quando não assumir nada em sua autorrelação que não seja ele mesmo. De acordo com seu critério, cada autorrelação mediada tem de ser desmascarada enquanto relação estranha que se aliena. Sob a orientação da norma de uma tal imediaticidade se baseia toda a crítica da religião, tomada de Feuerbach de maneira totalmente irrefletida e que depois ele não reivindica ao superar a imediaticidade do positivismo ingênuo de Feuerbach".
} 
na "Filosofia do Direito" de 1821 a separação moderna entre sociedade civil burguesa e Estado. Essa separação foi um resultado das revoluções modernas e produziu a despolitização da sociedade civil burguesa e a descentralização do poder político do Estado através do deslocamento do seu centro de gravidade para a economia (RIEDEL, 1982, p. 160). O princípio dos Estados modernos consiste, por um lado, em "deixar o princípio da subjetividade completar-se até o extremo autônomo da particularidade pessoal", ou seja, a sociedade civil burguesa e o Estado são esferas separadas que ganham autonomia. Por outro lado, esse princípio da moderna subjetividade é, ao mesmo tempo, reconduzido "à unidade substancial" do Estado ${ }^{3}$ (HEGEL, 1986, § 260, p. 407). Para Hegel, é importante a "Ideia de liberdade" como resultado de uma visão de mundo histórica da consciência moderna. Segundo ILTING (2006, p. 105), direito, moralidade e eticidade não são mais um "sistema normativo primário de ordenações da vida humana em conjunto, como era na filosofia política anterior a ele", mas sim, antes de tudo, "formas de visão de mundo" de um "desenvolvimento histórico de uma consciência".

Para Hegel (1986, § 182 Adendo), a "criação da sociedade civil pertence ao mundo moderno". Nela, a "unidade imediata da família desagregou-se numa multiplicidade" e o "[elemento] ético está aqui perdido nos seus extremos". Na segunda seção da "Filosofia do Direito", "A sociedade civil burguesa", é apresentado o significado especificamente moderno da contradição entre particularidade e universalidade: "Ao mesmo tempo em que na sociedade civil a particularidade e a universalidade estão dissociadas, estão ambas, contudo, reciprocamente ligadas e condicionadas" (§ 184 Adendo). Por um lado, a particularidade ganha direito à autonomia, enquanto os indivíduos são deixados livres para perseguir os seus próprios

${ }^{3}$ Para Riedel (1982, p. 138) fica claro na "Filosofia do Direito" que "o princípio do Estado moderno é poder suportar a oposição entre o bourgeois e o citoyen, de modo que ele mesmo a produz e a impulsiona até o seu cume dentro do pensamento como na efetividade". 
interesses. O Estado não é uma unidade ética imediata e não pode excluir o "direito da subjetividade" (§ 185 Adendo). Por outro lado, a universalidade se comprova tanto como o "fundamento e a forma necessária da particularidade" como também a "potência sobre ela e como o seu fim último" (§ 184), pois ela aparece como uma articulação de diferentes interesses em que cada indivíduo é meio para a satisfação das carências do outro, mas essa mediação se apresenta apenas como uma universalidade formal, pois ela não se encontra na consciência dos membros da sociedade civil (§ 187).

Essa mediação não permanece formal, pois o trabalho forma um caminho imanente da subjetividade livre em direção à universalidade. Através do trabalho da formação, a universalidade ganha "o conteúdo que a preenche e a sua autodeterminação infinita" (§ 187). Trata-se de um sistema de dependência e oposição do trabalho e de satisfação das carências em que "o egoísmo subjetivo se inverte na contribuição para a satisfação das carências de todos os outros" e o particular e o universal são mediados através de um "movimento dialético" (§ 199). Para Hegel, o universal e o objetivo do trabalho estão "na abstração, a qual efetua a especificação dos meios e das carências e com isso igualmente especifica a produção e produz a divisão dos trabalhos" (§ 198). Em consequência disso, surge com a divisão do trabalho uma correspondente formação teórica e prática nos diferentes estamentos (§ 201).

Para Hegel, os estamentos são, portanto, uma "divisão do todo" (§ 206 Anotação). A efetividade do indivíduo e, por conseguinte, sua particularidade determinada, está no pertencimento a um estamento, onde tanto a disposição de ânimo ética do indivíduo é formada, como também suas carências são restringidas (§ 207): “Um homem sem estamento é mera pessoa privada e não está numa universalidade efetiva" (§ 207 Adendo).

Essa proteção diante da contingência da existência na sociedade civil burguesa é completada pelas corporações. Através delas, "o elemento em si igual na particularidade vem à existência na associação cooperativa enquanto elemento comum" (§251). Segundo Hegel, 
a corporação tem o direito de cuidar dos seus próprios interesses ( $\$ 252)$. Nela, a "ajuda que a pobreza recebe perde o seu caráter contingente" e a atividade consciente é formada para um fim comum (§ 254). Por isso, a corporação é a "eticização do empreendimento isolado" (§ 255 Adendo) e constitui, ao lado da família, a "segunda raiz ética do Estado" (§ 255).

Através dessas instituições da sociedade civil burguesa, o "universal é, ao mesmo tempo, a causa de cada um, enquanto particular" e a sociedade civil burguesa aparece como ética ( $\$ 265$ Adendo). Por isso, as instituições sociais são a "base sólida do Estado" dentro da sociedade civil burguesa e a base "da confiança do indivíduo no Estado e da sua disposição de ânimo a favor dele", sendo por isso "os pilares da liberdade pública" (§ 265). Esta disposição de ânimo é a confiança de que o "meu interesse substancial e particular está conservado e contido no interesse e no fim de um outro (aqui, do Estado) enquanto esse está em relação comigo enquanto indivíduo singular". Neste sentido, o Estado é um imediato que não é nenhum um outro para o indivíduo (§ 256 Anotação; § 268).

A constituição política tem, portanto, uma significação abrangente, como "a organização do Estado e o processo da sua vida orgânica em relação a si mesmo, relação na qual ele diferencia os seus momentos no interior de si mesmo", e um restrito, como constituição enquanto tal, como poder legislativo, que é por ele desdobrada, ganhando subsistência (§ 271). Por isso, ela não é algo meramente feito e sim o "trabalho de séculos, a ideia e a consciência do racional, tanto quanto essa consciência está desenvolvida num povo" (§ 274 Adendo). A constituição é, portanto, a "solo firme e vigente" sob o qual está o poder legislativo ( $\$ 298$ Adendo). Este, por sua vez, pressupõe a constituição e é, ao mesmo tempo, "uma parte da constituição" (§ 298).

A constituição política é o "trabalho de séculos". Daí pode-se interpretar que ela é uma pressuposição histórica sob a qual está o poder legislativo. Neste sentido, Marx leu Hegel corretamente: Hegel pressupõe o Estado existente (MARX, 1982a, p. 58). Enquanto 
pressuposição histórica, a constituição política é tomada como uma dinâmica histórica que condiciona estruturalmente a formação social, dentro da apresentação da passagem da sociedade civil burguesa ao Estado considerado como "Ideia de liberdade". Contudo, enquanto pressuposição, ela está fora da determinação direta do poder legislativo: que o poder legislativo seja "apenas poder legislativo dentro da constituição" significa apenas que ele pode mudar a constituição apenas sobre determinadas condições históricas, que estão fora da determinação direta do poder legislativo. Por isso, a constituição obtém o seu desenvolvimento ulterior "no aperfeiçoamento contínuo das leis e no caráter progressivo dos assuntos universais do governo" (HEGEL, 1986, § 298). Segundo Marx, permanece aqui uma "oposição" e uma "colisão" entre a constituição e o poder legislativo. Essa colisão foi por ele compreendida como uma "contradição", cuja forma de desenvolvimento e de resolução foram concebidas por Hegel como mudança gradual da constituição ${ }^{4}$ (MARX, 1982a, p. 59-60).

Por um lado, Hegel considerou de maneira híbrida a sociedade civil burguesa ao tomar como pressuposições históricas a Revolução Francesa, a moderna economia inglesa ${ }^{5}$ e a realidade alemã ${ }^{6}$. Por outro lado, Hegel foi o mais consequente intérprete do Estado moderno em sua separação completa da sociedade civil burguesa ${ }^{7}$. Por isso, o poder legislativo foi por ele desenvolvido no sentido moderno. A sociedade

${ }^{4}$ Por isso, a contradição pode ser caracterizada na "Filosofia do Direito" como "colisão do finito": "A imediaticidade refletida do absoluto é em certa medida a forma de desenvolvimento constituída metafisicamente, na qual os contrapostos reais podem se mover. (...) Sobre essas pressuposições, a efetividade do direito se apresenta como aquela da luta pelo direito, cujo conteúdo e forma são determinados de maneira finita" (ARNDT, 1995, p. 91).

${ }^{5}$ Cf. HEGEL, 1986, § 189 Anotação: “É uma das ciências que surgiram na época moderna como seu terreno". Cf. também $\S 189$ Adendo: A Economia Política é "uma ciência que honra ao pensamento, porque ela encontra as leis para uma massa de contingências".

${ }^{6}$ Cf. RIEDEL, 1982, p. 186-7.

${ }^{7}$ Cf. MARX, 1982a, p. 176. 
civil burguesa e o Estado constituem, portanto, dois extremos completamente separados um do outro, mas essa separação é efetiva no Estado moderno.

A mediação dos extremos é apresentada por Hegel através dos estamentos da sociedade civil burguesa e de sua representação política no poder legislativo. Ela é uma mediação social do político através da qual o Estado não é nem um poder despótico e nem os interesses da sociedade civil burguesa se isolariam (HEGEL, 1986, § 302), pois as instituições sociais atingiriam no poder legislativo uma "significação e uma atuação políticas" (§ 303).

A crítica de Marx consiste em apresentar a mediação como existência da contradição e persistir na diferença dos extremos (cf. ARNDT, 1985, p. 262): “Extremos efetivos não podem ser mediados, justamente porque eles são extremos efetivos. Eles não precisam de nenhuma mediação, pois eles são essências contrapostas" (MARX, 1982a, p. 97). Por isso, Marx insiste no aspecto formal da representação política na "Filosofia do Direito". Para Hegel (1986, § 301), o "momento da liberdade formal subjetiva" vem à existência na representação estamental. Para Marx (1982a, p. 80), essa representação política é um mero "formalismo político". A sociedade civil burguesa é "em si e por si sem significação e eficácia políticas" (ibidem, p. 85). A instituição social tem, por isso, de renunciar a sua existência como estamento privado para atingir a "significação e eficácia políticas". Por conseguinte, o burguês efetivo se encontra em uma "dupla organização" - na organização social e na organização estatal. Para se comportar como cidadão efetivo do Estado, o burguês tem em sua individualidade de se retirar da organização social, pois "a única existência que ele encontra para a sua atuação como cidadão do Estado é a sua individualidade pura e nua", pois a existência do Estado está completa sem ele e a sua existência na sociedade civil burguesa está também completa sem o Estado. Assim, o indivíduo só pode ser cidadão do Estado quando está "em contradição com essas únicas comunidades aí-presentes" da sociedade civil burguesa. Neste sentido,

90 O conceito Marxiano de contradição na crítica à Filosofia do Direito de Hegel 
o poder legislativo repõe a atomização dos indivíduos na sociedade civil burguesa ao invés de repolitizar esta. A vida burguesa e política permanecem separadas uma da outra.

O conceito marxiano de contradição parte de pressuposições históricas que são diferentes das de Hegel. Este tem como ponto de partida histórico uma sociedade civil burguesa em que os indivíduos se articulam em corporações, comunas e associações cooperativas. Assim, eles mantêm uma conexão política (HEGEL, 1986, § 308). Marx (1982a, p. 121) pressupõe uma sociedade civil burguesa em que os indivíduos estão atomizados e só se reúnem "por um instante sem sustentação ulterior, para um ato isolado e temporário" - o voto. Sua pressuposição é, portanto, a transformação dos estamentos políticos em estamentos sociais realizada pela Revolução Francesa, de modo que a vida política não tem mais significado na sociedade civil. Daí segue que o elemento democrático é, nos tempos modernos, uma "abstração do Estado apenas político" e uma "abstração da sociedade civil burguesa de si mesma" (ibidem, p. 123). Portanto, a contradição do poder legislativo, impulsionada à manifestação, é a contradição do poder legislativo e da sociedade civil burguesa consigo mesma (ibidem, p. 100).

Desse modo, a crítica da constituição do Estado atual deve mostrar não apenas a contradição como existente, mas também esclarecer a sua "necessidade" e conceituar a sua "gênese". O conceituar consiste apenas em apreender "a lógica própria do próprio objeto" (ibidem, p.101). Segundo Marx, a contradição tem uma forma histórica específica. Esta forma é a constituição representativa na França ${ }^{8}$ (MARX, 1982a, p. 130). É uma aspiração efetiva da sociedade civil burguesa dar um seraí político para si mesma (ibidem, p. 128), mas a exigência de que cada carência social seja através do Estado reconhecida como política em seu sentido social toma, no Estado político, um sentido formal, que cai fora do conteúdo efetivamente social. Isso não é nenhuma abstração dos franceses, mas sim uma consequência da existência do Estado moderno

${ }^{8}$ Cf. KURT, 1975, p. 260-1. 
efetivo (ibidem, p. 130). A contradição se situa, aqui, dentro do sistema do Estado político efetivo, sob a pressuposição histórica da separação completa entre o Estado e a sociedade civil burguesa impolítica. A eleição é, entretanto, a relação imediata da sociedade civil burguesa com o Estado político (ibidem, p. 130). A constituição representativa é um progresso, pois ela é a contradição declarada e a expressão consequente da situação moderna do Estado. A eleição - enquanto relação existente da sociedade civil burguesa com o Estado - é a forma específica de movimento da contradição da constituição representativa. A constituição representativa é finita porque ela é em si contraditória: a relação contraditória da sociedade civil burguesa com o Estado é, ao mesmo tempo, a sua formação política - sua repolitização; através da eleição irrestrita, a sociedade civil burguesa conclui a abstração de si mesma e essa conclusão é, ao mesmo tempo, a exigência de dissolução do Estado político e da sociedade civil burguesa ${ }^{9}$. Isso significa que as condições de existência da contradição são dissolvidas ${ }^{10}$.

Marx está certo quando diz que, segundo a concepção de Hegel, as oposições assumem na "Filosofia do Direito" também uma "figura material" (ibidem, p. 107). Apesar disso, Hegel parte de outras pressuposições históricas, ou melhor, de uma sociedade civil

${ }^{9}$ Cf. MARX, 1982a, p. 130: "Somente a partir do direito irrestrito tanto de escolher como de ser eleito, a sociedade civil burguesa se alça efetivamente à abstração de si mesma, ao ser-aí político enquanto seu ser-aí verdadeiro, universal e essencial. Mas a conclusão dessa abstração é, ao mesmo tempo, a suspensão da abstração. Ao pôr o seu ser-aí político como verdadeiro [ser-aí político], a sociedade civil burguesa pôs, além disso, o seu ser-aí burguês como uma diferença inessencial em relação ao seu ser-aí político; e com isso cai a separação, o seu outro, o seu contrário. A reforma eleitoral é, portanto, dentro do Estado político abstrato, a exigência de sua dissolução e igualmente a exigência de dissolução da sociedade civil burguesa".

${ }^{10} \mathrm{Na}$ democracia não há nenhuma determinidade diferente de outro conteúdo, pois a própria constituição aparece "apenas como uma determinação, ou melhor, como autodeterminação do povo", ou seja, não há uma significação dupla entre a vida social e política. Isso significa, por conseguinte, a dissolução dos extremos, ou melhor, das condições de existência da contradição: "Os novos franceses compreenderam que o Estado político perece na verdadeira democracia. Isso é certo na medida em que ele como Estado político, como constituição, não vale mais para o todo" (ibidem, p. 30-2). 
burguesa em que os indivíduos estariam "articulados em corporações, comunas e associações cooperativas" e "dessa maneira adquirem uma conexão política", ou seja, "o membro do Estado é membro de um tal estamento" (HEGEL, 1986, § 308). Através dos estamentos, a sociedade civil burguesa e o Estado, enquanto extremos constituídos, estariam mediados e a oposição é reduzida a uma aparência (§ 302 Anotação). Isso ocorre porque o Estado, considerado como Ideia de liberdade, dá aos estamentos uma significação moderna. Por isso, a significação política dos estamentos tem de ser outra daquela da sociedade civil ${ }^{11}$.

Na justificação do morgadio se torna claro que Hegel procura apresentar, através do elemento da tradição, tanto uma mediação social do político como também uma limitação para a "extravagância" da sociedade civil burguesa ${ }^{12}$ (HEGEL, 1986, § 185). Através do estamento dos proprietários fundiários vem à existência a mediação entre os extremos da universalidade empírica da sociedade civil burguesa e o poder do príncipe. Esse estamento está em condições de constituir essa significação política, pois, por um lado, ele tem a imediaticidade ética da vida familiar e a determinação natural do poder do príncipe (§ 305); por outro lado, ele compartilha das mesmas carências e direitos da sociedade civil burguesa. Por isso, ele se torna, ao mesmo tempo, o sustentáculo do trono e da sociedade (§307). Sua posição e significação política consiste que o patrimônio desse estamento é "independente tanto do patrimônio do Estado como da insegurança da indústria, da busca compulsiva do ganho e da mutabilidade da posse em geral" (§ 306). O morgadio é justificado apenas porque ele pode aumentar a segurança e a estabilidade desse estamento, já que o Estado não pode

${ }^{11}$ Em oposição à crítica de Marx, não seria nenhum problema, segundo a concepção de Hegel, que o Estado desse ao estamento privado "uma significação política, isto é, uma outra significação, enquanto sua significação efetiva" (MARX, 1982a, p. 77).

12 "Ao articular conceitualmente o processo histórico-político decisivo da modernidade - a separação da sociedade do Estado e a relação recíproca entre tradição e revolução -, ele torna possível pensar a figura moderna da sociedade civil burguesa e, ao mesmo tempo, limitar o seu poder substancial através de estruturas antigas" (RIEDEL, 1982, p. 169). 
"contar com a mera possibilidade da disposição de ânimo, porém com algo necessário" (§ 306 Adendo).

Para Marx, a justificação de Hegel do morgadio é um "sincretismo": "Hegel quer o sistema estamental da Idade Média mas no sentido moderno do poder legislativo". A crítica de Marx tem uma dupla significação: por um lado, ele constata uma "acomodação" de Hegel (MARX, 1982a, p. 105); por outro lado, ele descobre que a propriedade privada foi apresentada por Hegel na "mais alta autonomia e precisão de seu desenvolvimento", pois o morgadio é a propriedade privada que se libertou de todas as amarras sociais e éticas. Portanto, quando o Estado dá ao morgadio uma significação moderna, ele conduz a propriedade privada a sua "autonomização

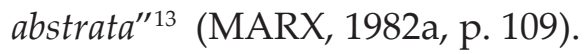

\section{III}

Da crítica de Marx à "Filosofia do Direito" de Hegel é possível concluir que (1) o conceito marxiano de contradição parte de pressuposições históricas diferentes das de Hegel: enquanto Marx pressupõe uma sociedade em que os indivíduos estão atomizados, Hegel pressupõe uma em que esses estão articulados em estamentos. Daí segue que (2) os extremos, segundo Marx, não podem ser mediados e, para Hegel, os estamentos podem desempenhar o papel da mediação. Nesta perseverança da diferença da contradição na dialética de Marx é possível apreender que (3) Hegel e Marx têm diferentes procedimentos para tratar as pressuposições históricas: as pressuposições históricas assumem uma nova forma na dialética hegeliana, por isso a Ideia de

\footnotetext{
${ }^{13}$ Essa análise aponta a meu ver para a relação moderna entre Estado e propriedade privada capitalista. Cf. Henry (1976, p. 65): “C'est alors le rapport du politique et de l'économie qui se trouve posé lui aussi pour la première fois, de façon explicite, dans l'œuvre de Marx et sa solution échappe à toute équivoque. L'économie n'est pas l'essence, n'est pas la réalité et ne saurait la définir ni la déterminer, être un principe de détermination".
} 
Estado está em condições de dar aos estamentos uma significação política moderna; em oposição a isso, as pressuposições reais são apenas reproduzidas pela dialética marxiana. A partir desses diferentes tratamentos da história segue que, (4) em relação às formas de movimento da contradição, as concepções de Hegel e Marx diferem uma da outra: (a) na filosofia hegeliana do direito, a Ideia de liberdade constitui a forma de desenvolvimento da contradição na qual a constituição é aperfeiçoada através do poder legislativo. Portanto, contradição é aqui entendida como "colisão do finito". Essa colisão entre a constituição historicamente desenvolvida e o poder legislativo é limitada porque ela aponta para a formação histórica do Estado. Esta, por sua vez, é subordinada à relação dos Estados entre si. Nessa relação, a autonomia do Estado é exposta à contingência exterior. Trata-se aqui de uma "dialética da finitude", através da qual o irrestrito "Espírito do mundo" se produz (cf. Hegel, 1986, § 30, p. 340). A contradição contem na "Filosofia do Direito" uma forma de desenvolvimento que é condicionada pela Ideia de liberdade. Essa forma aponta para uma "nova instância da filosofia prática" - a história (RIEDEL, 1982, p. 219). Esta, por um lado, não abole a contradição, mas é a esfera de legitimação de cada liberdade que tem sua efetividade na constituição do Estado do mundo moderno ${ }^{14}$; (b) Marx, por sua vez, concebe a forma de movimento da contradição como dada através de uma condição de existência que é historicamente pressuposta (ARNDT, 1985, p. 261). O desenvolvimento da contradição também aponta para uma esfera da história, ou melhor, para a condição de existência da contradição. A história tem aqui como ponto de vista a contradição entre a moderna constituição representativa e a dissolução consumada da identidade entre os estamentos políticos e sociais. A contradição é a "contradição do Estado político, portanto, também da sociedade civil burguesa consigo mesma" (Marx, 1982a, p. 100, grifo meu). Por isso, trata-se aqui

\footnotetext{
14 "A história enquanto o progresso na consciência de liberdade é a justificação de cada liberdade que tem sua efetividade na constituição do Estado do mundo moderno" (RIEDEL, 1982, p. 220).
} 
também de uma dialética da finitude, pois a contradição aponta para a finitude do Estado político efetivo e da sociedade civil burguesa efetiva, já que a eleição - enquanto a relação efetiva da sociedade civil burguesa com o Estado político - "forma o principal interesse político da sociedade civil burguesa efetiva" (ibidem, p. 130). A aspiração pela eleição irrestrita é a aspiração da sociedade civil burguesa para se transformar em sociedade política (ibidem, p. 128). Por isso, a eleição irrestrita é, ao mesmo tempo, enquanto a abstração completa da sociedade civil burguesa de si mesma, a "suspensão da abstração", isto é, a exigência de dissolução do Estado político e da sociedade civil burguesa (ibidem, p. 130). Através da indicação de um campo histórico, a dialética se abre para uma outra instância, a da práxis política $^{15}$ - aqui, a reforma política enquanto ponto de partida para uma democracia que se radicaliza. Esta alusão a um campo de atuação política permanece aqui vaga, pois, por um lado, a situação histórica no começo dos anos 1840 não se deixava especificar ${ }^{16}$; por outro lado, a dialética marxiana ainda não podia indicar onde especificamente a consideração histórica tem de entrar em seu método e em que lugar o poder se estabelece e é atacável.

\section{Bibliografia}

ARNDT, Andreas. Karl Marx. Versuch über den Zusammenhang seiner Theorie. Bochum: Germinal, 1985.

\footnotetext{
${ }^{15}$ Aqui se encontra uma diferença declarada entre Marx e Feuerbach: “Os aforismas de Feuerbach não são justos para mim em um ponto, pois ele aponta muito para a natureza e muito pouco para a política". (MARX, 1975b, p. 45).

${ }^{16}$ A dialética marxiana já era capaz de apontar para uma ação política que lançasse uma ponte entre o campo de experiências e o horizonte de expectativas, mas as expectativas postas pela Revolução Francesa ainda precisavam ser trabalhadas por meio do desenvolvimento de novas experiências (cf. KOSELLECK, 1989, p. 372-4).
} 
. "Der Begriff der Allgemeinheit in der Philosophie des Rechts". In: ARNDT, A.; BAL, K., OTTMANN, O. (org.) Hegel-Jahrbuch 1993/1994. Berlin: Akademie Verlag, 1995. p. 89-97.

HEGEL, Georg Wilhelm Friedrich. Grundlinien der Philosophie des Rechts oder Naturrecht und Staatswissenschaft im Grundrisse. Edição de Eva Moldenhauer e Karl Markus Michel. Frankfurt/M: Suhrkamp, 1986.

HENRY, Michel. Marx I: une philosophie de la réalité. Paris: Gallimard, 1976.

ILTING, Karl-Heinz. "Die logische und systematische Form der Rechtsphilosophie". In: BECCHI, Paolo; HOPPE, Hansgeorg (org.). Karl-Heinz Ilting. Aufsätze über Hegel. Frankfurt/M: Humanities, 2006. p. 100-112.

KOSELLECK, Reinhart. Vergangene Zukunft. Zur Semantik geschichtlicher Zeit. Frankfurt am Main: Suhrkamp, 1989.

KURT, Röttgers. Kritik und Praxis. Zur Geschichte des Kritikbegriffs von Kant bis Marx. Berlin; New York: Walter de Gruyter, 1975. (Quellen und Studien zur Philosophie).

MARX, Karl. Zur Kritik der Hegelschen Rechtsphilosophie. MEGA, I/2. Berlin: Dietz, 1982a. p. 3-137.

. Zur Kritik der Hegelschen Rechtsphilosophie. Einleitung. MEGA, I/2. Berlin: Dietz, 1982b. p. 170-183.

. Karl Marx an Arnold Ruge. Kreuznach, September 1843. MEGA, III/1. Berlin: Dietz, 1975a. p. 54-57.

. Karl Marx an Arnold Ruge. 13. März 1843. MEGA, III/1. Berlin: Dietz, 1975b. p. 44-46. 
RIEDEL, Manfred. Zwischen Tradition und Revolution: Studien zu Hegels Rechtsphilosophie. Stuttgart: Klett-Cotta, 1982.

THEUNISSEN, Michael. Sein und Schein. Die kritische Funktion der Hegelschen Logik. Frankfurt am Main: Suhrkamp, 1978.

YILDIZ, Ersin. "Marx' verfassungstheoretische Schriften und die Entwicklung der materialistischen Rechtstheorie". In: HIRSCH, Joachim; KANNANKULAM, John; WISSEL, Jens. (org.). Der Staat der Bürgerlichen Gesellschaft. Zum Staatsverständnis von Karl Marx. Baden-Baden: Nomo.

\begin{tabular}{l|l}
\hline 98 & O conceito Marxiano de contradição na crítica à Filosofia do Direito de Hegel
\end{tabular} 